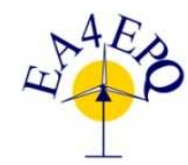

International Conference on Renewable Energies and Power Quality (ICREPQ'13)

Bilbao (Spain), $20^{\text {th }}$ to $22^{\text {th }}$ March, 2013

Renewable Energy and Power Quality. Tournal (RE\&PQJ)

ISSN 2172-038 X, No.11, March 2013

\title{
Who pays for harmonic network losses caused by PV inverters?
}

\author{
J. Kiss and A. Dan \\ Department of Electric Power Engineering \\ Budapest University of Technology and Economics \\ Egry Jozsef u. 18 . V1 bdg. $3^{\text {rd }}$ floor, H-1111 Budapest (Hungary) \\ Phone/Fax number: +36 1463 2904, e-mail: kiss.jozsef@ vet.bme.hu, dan.andras@ vet.bme.hu
}

\begin{abstract}
The even growing number of small power (household rate) PV sets and the connecting inverters should warn utility companies to make a reconsideration on the network losses. Of course the main portion of the network losses is in connection with the fundamental current flow along the network. In our former papers [1], [2] and [3] it was pointed out that the harmonic network losses caused by non-linear loads generating harmonic currents actually are paid, because the non-linear loads receive as additional fundamental power the network losses originating by their generated harmonic currents.

The PV inverter is a fundamental current power generator, but as a nonlinear element it generates harmonic currents as well. The fundamental current network loss cannot be separated into parts caused by consumption and generation; therefore the utility pays for the total energy supplied by the PV installation including the network loss. And what is the situation regarding the harmonic network loss?

The paper gives a theoretical overview of the problem, furthermore - based on laboratory measurements - a proper computer simulation model was developed. Using computer simulations different practical scenarios are discussed.
\end{abstract}

\section{Key words}

Power Quality, Computer Simulation, PV Systems, Harmonic Distortion, Metering Accuracy

\section{Introduction}

The non-linear loads generate harmonic currents. These harmonic currents are injected into the supply network. The harmonic losses depend on the resistive part of the harmonic driving point impedance measured at the PCC of the nonlinear load. The fundamental harmonic network loss can not be measured at the consumer revenue meter. However the harmonic network loss will be measured, because the received fundamental frequency energy increases with the actual harmonic network loss caused by the non-linear load in question. But what about with nonlinear generators? The PWM inverters connected to the supply network as the network-side energy converters of a wind farm or a PV farm are non-linear element as well, however they are generators. The question is the estimation of the network losses due to these kind of generators.

It was pointed out in many papers that the distributed generation can highly affect the network losses [4], [5] and [6]. In special cases the losses can even be bigger than without distributed generation. The actually arising losses depend on many factors, including the placement of the generator, the network parameters, the rated power of the plants, the load rate of the district, etc.

It is also known that the network losses consist of fundamental and harmonic components [7], [8]. The studied PV inverters are nonlinear elements as well, so they can affect the harmonic content of the network and thereby the harmonic loss components [9], [10]. Many papers study the possibilities to reduce the harmonic distortion of these inverters or to use them to reduce the existing harmonic distortion on the network [11], [12].

\section{Harmonic powers and losses}

Let us consider a battery based energy storage system, connected to the supply network by a front end PWM inverter, and the inverter can work in battery charger mode- like a non-linear load- or in generator mode -like a non-linear generator discharging the battery. At a given moment the fundamental power network loss can not be separated from the active power supplied into the network, the power measured at the PCC of the non-linear generator consists of the network loss as well as the power consumed by the loads. Regarding a battery storage system the fundamental power network loss could be estimated from the voltage changes measured in charging and discharging mode. The load rate of the district has a significant impact on the actual fundamental network loss in discharging mode. This question will be discussed in a later paper.

The harmonic network loss is a more complicated question, because of the interaction of the harmonic currents and voltage distortions. This interaction means a network reaction (current-voltage) and a PWM control interaction (voltage-current). Formally the harmonic 
network loss is calculated as the real part of the $V_{h} \cdot I_{h}$ phase by phase. Therefore a non-dominant non-linear element (load or generator) can cause positive or negative harmonic network loss at its PCC. However a dominant non-linear generator will cause harmonic losses in the network connected thereto and the supplied fundamental energy will be less according to the actual harmonic losses, because the total energy is covered by the primary energy like wind or sun. In this paper the problem of the harmonic losses is discussed based on computer model and site measurements.

\section{The developed computer model}

In order to study the harmonic network losses a simple computer model was built in MATLAB environment. The developed model is intended to simulate the operation of a PWM inverter connected to a low voltage network. Fig. 1. shows the schematics of the applied model, which consists of three main components:

- The inverter

- The low voltage supply network

- An electrical line connecting the previous two components

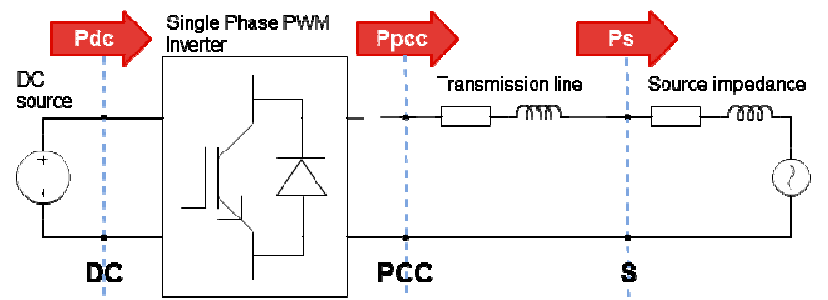

Fig. 1. Schematic of the applied MATLAB model

The low voltage supply network is represented by its Thévenin equivalent whose nominal fundamental $(50 \mathrm{~Hz})$ line to ground voltage is $230 \mathrm{~V}_{\text {RMS }}$. The ratio of the resistive and reactive components of the source impedance was chosen to be unity, just like the same parameter of the above mentioned electrical line. This value is considered as a reasonable assumption in case of a low voltage network. The impedance of the electrical line was chosen to be $(1+\mathrm{j} 1) \Omega$ at the fundamental frequency. It is vital for our studies to be able to simulate a harmonically distorted supply network as well. According to this requirement the harmonic content of the voltage source can be freely changed.

The applied inverter is a single phase full bridge inverter with PWM controlled current control. The converter consists of ideal switching devices since this paper does not aim to study the losses arising inside the inverter. The applied switching frequency is $10 \mathrm{kHz}$. There is a voltage source on the DC side which is ideal as well. The inverter is connected to the grid through a coupling inductor that is needed by the current control. Due to this solution the injected current of our nonlinear generator can be set in a wide range. At the fundamental frequency our generator operates with a unity power factor according to the actual regulations.

Measurements are taken at three special points: at the point of common coupling (PCC) where the converter connects to the grid, at the output of the DC source (DC) and where the electrical line is connected to the supply network (S). The installed meters measure the active power at all important frequencies.

\section{Calculation results}

Using the above described simple computer simulation model different practical scenarios were studied. The results of these calculations are described in this section. Table I. shows the calculated results for all scenarios.

The coupling inductor which connects the inverter to the network has a small resistive component as well. Accordingly, the current flowing through this resistance causes loss. We considered it as the inner loss of the converter, and therefore the published DC power values are decreased with this loss value.

Table I. - Calculated active power in different scenarios

\begin{tabular}{|c|c|c|c|c|c|c|c|}
\hline \multicolumn{8}{|c|}{ Calculated active power [W] } \\
\hline \multirow{2}{*}{ 心్ } & \multirow[t]{2}{*}{ DC } & \multicolumn{3}{|c|}{ PCC } & \multicolumn{3}{|c|}{$\mathbf{S}$} \\
\hline & & $50 \mathrm{~Hz}$ & $150 \mathrm{~Hz}$ & $250 \mathrm{~Hz}$ & $50 \mathrm{~Hz}$ & $150 \mathrm{~Hz}$ & $250 \mathrm{~Hz}$ \\
\hline 1 & 2400 & 2400 & 0 & 0 & 2300 & 0 & 0 \\
\hline 2 & 2422 & 2401 & 4 & 17 & 2301 & 0 & 1 \\
\hline 3 & 2436 & 2401 & 9 & 26 & 2301 & 5 & 10 \\
\hline 4 & 2408 & 2400 & 0 & 7 & 2300 & -4 & -9 \\
\hline 5 & 2360 & 2401 & -10 & -31 & 2301 & -14 & -47 \\
\hline
\end{tabular}

\section{A. Case 1}

This case can be considered as ideal, because the supply network is undistorted and the adjusted current of the inverter does not contain any harmonics. For the sake of completeness it should be mentioned that the actually injected current is not clearly fundamental because of the working principle of the PWM inverter. Nevertheless, this distortion is much less than the adjusted distortions in the following scenarios. The total harmonic distortion of the injected current is only $1.04 \%$ therefore the losses caused by these harmonics are negligible in comparison with the fundamental losses. The inverter injects $10 \mathrm{~A}_{\mathrm{RMS}}$ current into the network.

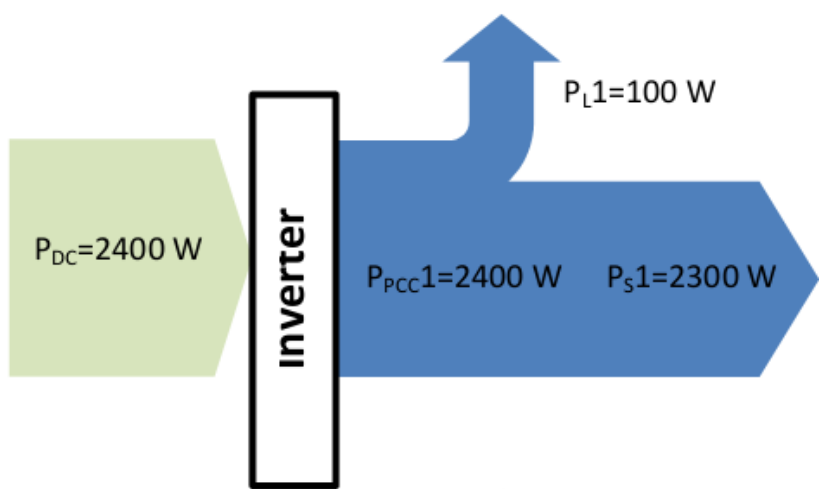

Fig. 2. (Case 1) Undistorted voltage source and fundamental current source.

As can be seen in Fig. 2., the calculated DC power is equal to the total power measured at PCC. However, the total active power at the point $\mathrm{S}$ is less than at PCC. The 
difference between the two values is the fundamental line loss. This loss is covered by the power generated by the DC source. The revenue meter installed at the PCC measures the total amount of energy at that point, so the utilities have to pay for the fundamental network loss as well.

\section{B. $\quad$ Case 2}

This scenario differs from the previous case in the harmonic content of the injected current. The inverter generates a $3^{\text {rd }}$ harmonic current of $2 \mathrm{~A}_{\mathrm{RMS}}$ and a $5^{\text {th }}$ harmonic current of $4 \mathrm{~A}_{\mathrm{RMS}}$ besides the above mentioned fundamental component. This means an adjusted total harmonic distortion of $45 \%$, which seems to be quite excessive. However, the high level of the harmonic currents increases the network losses, which help us understand the nature of the problem. The low voltage supply network is still undistorted. The simulation results are given in Fig. 3.

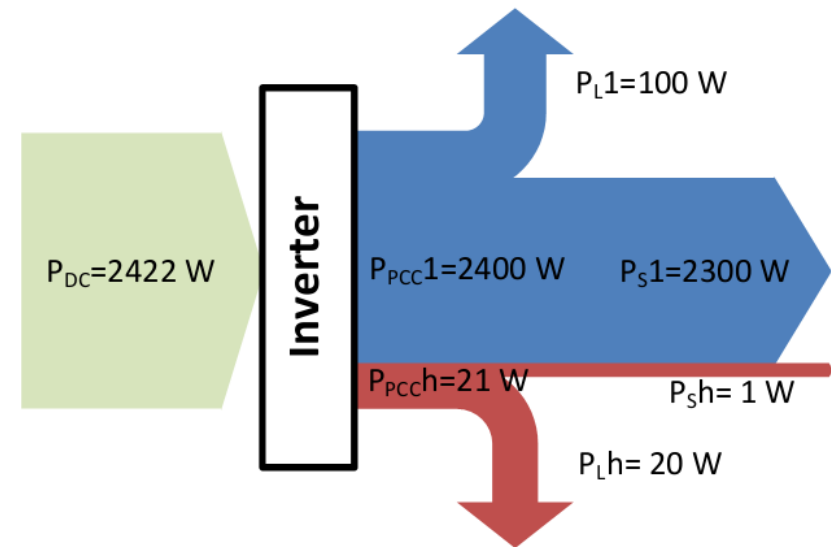

Fig. 3. (Case 2) Undistorted voltage source and distorted current source.

According to the above described conditions the converter is the dominant (and the only one) nonlinear element on the network. The inverter converts the received DC power into fundamental and harmonic power. The resultant power measured at the PCC is higher than in the previous case. The difference is the harmonic power which is equal to the harmonic losses on the entire network (electrical line and source impedance). Therefore the utilities have to pay for the fundamental and harmonic losses as well.

The harmonic currents flowing through the network cause voltage drop on the source impedance. Although the supply network is undistorted, harmonic voltage can be measured at the point $\mathrm{S}$.

The adjusted harmonic currents are the same in all the studied scenarios, so the arising network losses will be the same as well.

\section{C. $\quad$ Case 3}

So far the voltage source was undistorted. In this scenario not only the PV generator but also the supply network is distorted. The adjusted $3^{\text {rd }}$ and $5^{\text {th }}$ harmonic voltages are $7 \mathrm{~V}_{\mathrm{RMS}}$ and $12 \mathrm{~V}_{\mathrm{RMS}}$ respectively. The phase angles of the adjusted harmonic voltages were chosen to be equal to the previously calculated values (Case 2). The results can be seen in Fig. 4.

In this case the studied inverter is not the only nonlinear element on the network, but the others have similar harmonic characteristics. The results show some similarity to the previous case. The network losses, both fundamental and harmonic, are covered by the DC side. The total power measured at PCC is higher than in the previous but the direction of the power flow did not change.

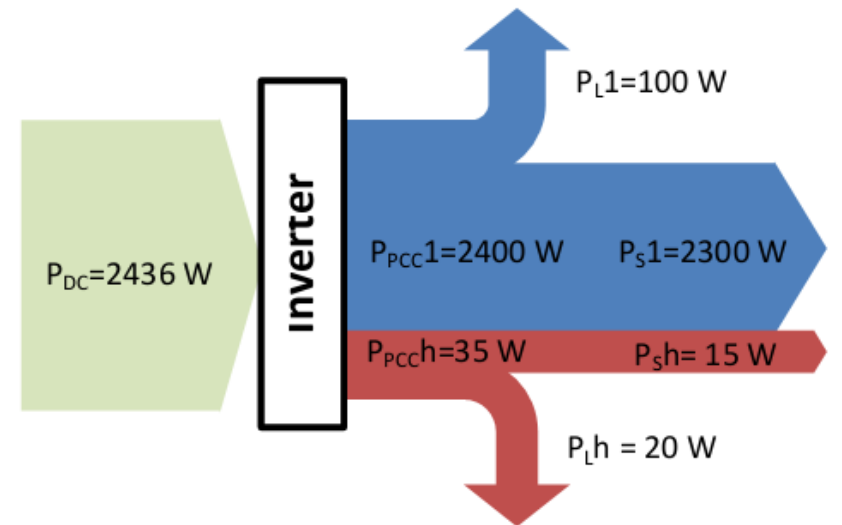

Fig. 4. (Case 3) Distorted voltage source and distorted current generator. The phase angles of the harmonic voltages are identical with the previous case.

\section{D. $\quad$ Case 4}

In this scenario the generated current and the supply voltage are distorted again. Although the magnitudes of the harmonic voltages are unchanged, their phase angles differ from the previous case with 180 degrees. It means that the studied inverter is neither the only nonlinear element on the network, nor the dominant one. The calculated results are given in Fig. 5.

As it can be seen in the figure, the DC side and the supply network cover the harmonic losses together. The total power at the connection point of the inverter is still higher than the fundamental component.

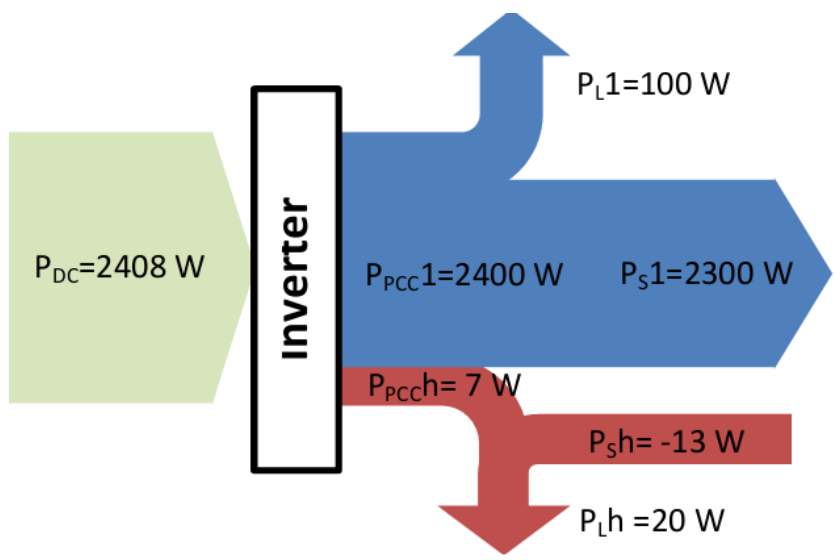

Fig. 5. (Case 4) Distorted voltage source and distorted current source. The phase angles of the harmonic voltages are 180 degrees different from the previous case.

\section{E. $\quad$ Case 5}

This is a special scenario where the phase angle between the harmonic currents and voltages is 180 degrees at the point $\mathrm{S}$, so the calculated active harmonic power at this point has only active component. The adjusted current and voltage magnitudes are still unchanged. According to Fig. 6 , the direction of the harmonic power flow has changed. The inverter receives harmonic power from the supply network and converts it into fundamental frequency active power. The DC power, which is also equal to the total 
power at PCC, is less than the measured fundamental power at the connection point of the nonlinear generator. For this reason the utility pays less, than the produced fundamental energy. Naturally, the supply network covers the harmonic line losses.

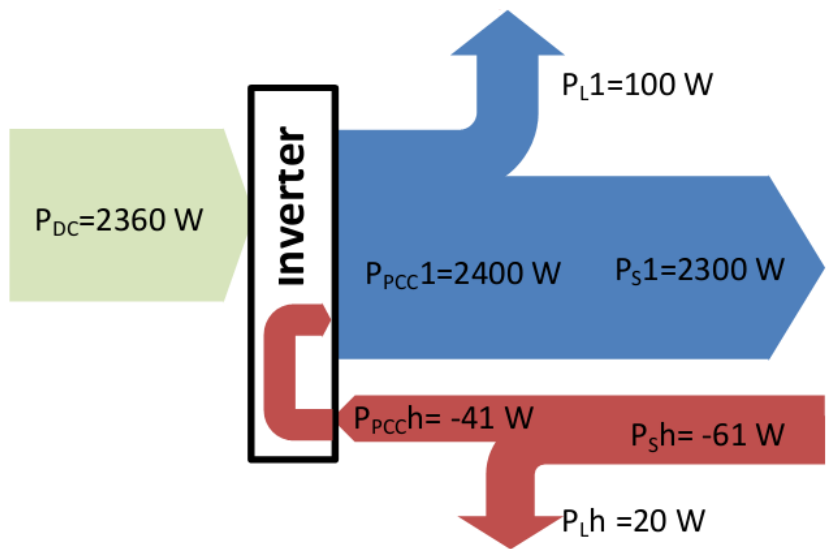

Fig. 6. (Case 5) Distorted voltage source and distorted current source. The phase angle between the harmonic voltages and the corresponding currents is 180 degrees at the point $\mathrm{S}$.

\section{Results of site measurements}

As it was mentioned in section 2 a PWM modulated battery based energy storage system was measured with $500 \mathrm{~kW}$ rated power. The $0.4 \mathrm{kV}$ side voltage distortion was basically independent from the inverter generated current distortion, therefore no significant change in the harmonic power at the PCC was measured. It proves the results of computer simulation, that the harmonic network losses depend on the domination level of the non-linear element identically to the harmonic load situation. As an example the results of a charging-discharging process is shown in Fig.7. The fundamental power (charging is positive) and the harmonic powers are shown as time functions.

\section{Conclusions}

It can be concluded that the utilities always pay for the total energy supplied by the PV inverters, including the fundamental network losses as well. In case of harmonic losses the situation is not so obvious. The signs of the harmonic powers depend on the phase angles between the corresponding harmonic voltage and current.

Because the harmonic current distortion of the PWM inverters is limited in 5\% and the sign of the harmonic powers change stochastically, the authors recommend to neglect the harmonic network losses, caused by PWM inverters fulfilling the standard recommendations.

\section{Acknowledgement}

The work reported in the paper has been developed in the framework of the project ,Talent care and cultivation in the scientific workshops of BME" project. This project is supported by the grant TÁMOP-4.2.2.B-10/1--2010-0009.

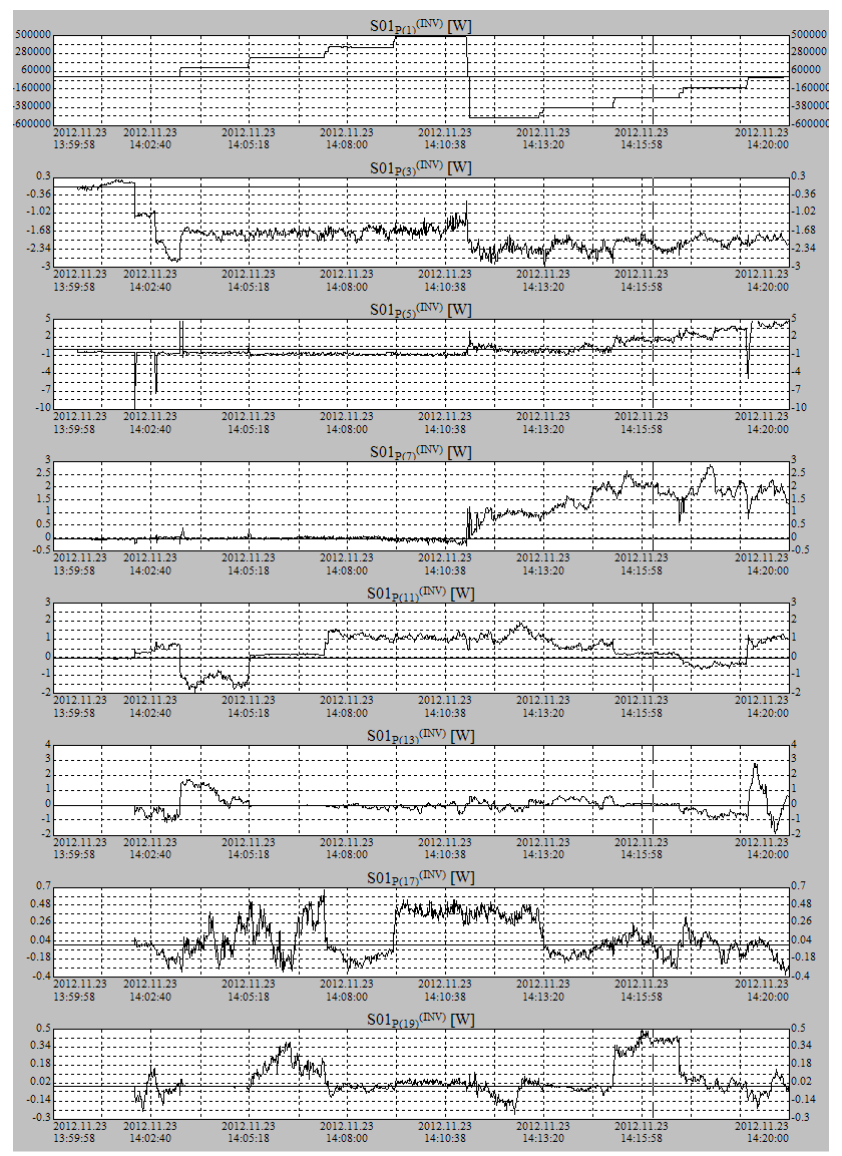

Fig.7. Measured fundamental and harmonic powers at the PCC of the $500 \mathrm{~kW}$ battery based energy storage system.

\section{References}

[1] Dán A, Raisz D, Hornyák L, Rios S, "Power consideration and digital energy metering accuracy on distorted network", in 48th Internationales Wissenschaftliches Kolloquium. Ilmenau, Germany, 2003. pp. 42-47. Paper I111.

[2] Dán András, Raisz Dávid Márk, Sebastian Rios, "Summary of the Results of Digital Energy Meter Accuracy on Distorted Networks", in 4th International Conference on Electric Power Quality and Supply Reliability. Pedase, Estonia, 29-31.08.2004.

[3] Dán András, Raisz Dávid Márk, "What do and what should our digital revenue meters measure on distorted networks?" in 11 th International Conference on Harmonics and Quality of Power 2004 (ICHQP), Lake Placid, USA, 12-15.09.2004. Paper 064.

[4] P. Chiradeja: "Benefit of Distributed Generation: A Line Loss Reduction Analysis", in Transmission and Distribution Conference and Exhibition: Asia and Pacific, 2005 IEEE/PES, pp. $1-5$.

[5] M. Sedighizadeh, M.R. Bayat, M.E. Khodayar, "Using genetic alghoritm for distributed generation allocation to reduce losses and improve voltage profile", in 42nd International Universities Power Engineering Conference, 2007. UPEC 2007., 4-6 Sept. 2007, pp. 954-959

[6] V.H.M. Quezada, J.R. Abbad and T.G.S. Roman, "Assessment of energy distribution losses for increasing penetration of distributed generation", in IEEE Transactions on Power Systems, May 2006, Vol. 21, Isssue 2, pp. 533-540.

[7] A. Dán, T. Tersztyánszky and Gy. Varjú, Power Qualty, Budapest, Hungary, Invest-Marketing Ltd. (2006), book in Hungarian

[8] Dán András, Raisz Dávid Márk, "Unified loss theory and its application on low voltage networks", in International Conference on Renewable Energy and Power Quality 
(ICREPQ'09). Santander, Spain, 2008.03.12-2008.03.14. pp. 1-9. Paper IS4

[9] H. Farooq, C. Zhou, M.E. Farrag, M. Ejaz, "Investigating the Impacts of Distributed Generation on an Electrical Distribution System Already Stressed by Non-Linear Domestic Loads", in Power and Energy Engineering Conference (APPEEC), 2012 Asia-Pacific, 27-29 March 2012, pp. 1-4.

[10] L. Degroote, B. Renders, B. Meersman and L. Vandevelde, "Influence of converter-based distributed generators on the harmonic line losses", in 13th International Conference on Harmonics and Quality of Power, 2008. ICHQP 2008., Sept. 28 2008-Oct. 1 2008, pp. 1-6.

[11] G. Joos, B.T. Ooi, D. McGillis, F.D. Galiana, R. Marceau, "The Potential of Distributed Generation to Provide Ancillary Services", in 2000. IEEE Power Engineering Society Summer Meeting, pp. 1762 - 1767 vol. 3.

[12] M. Prodanovic, K. De Brabandere, J. Van den Keybus, T. Green, J. Driesen, "Harmonic and reactive power compensation as ancillary services in inverter-based distributed generation", in IET Generation, Transmission \& Distribution, May 2007, Vol. 1, Isssue 3. pp. 432-438.

József Kiss received the B.Sc. and M.Sc degrees in electrical engineering from Budapest University of Technology and Economics, Budapest, Hungary, in 2008 and 2010, respectively.

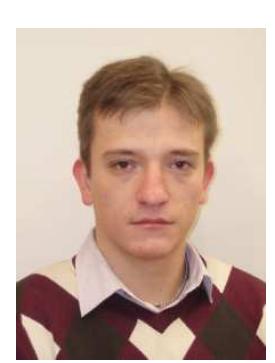

Currently, he is a $\mathrm{PhD}$ student at Department of Electric Power Engineering at the same University. He is a member of the Hungarian Electrotechnical Association.

His main field of interest is network losses, especially network losses caused by harmonics.

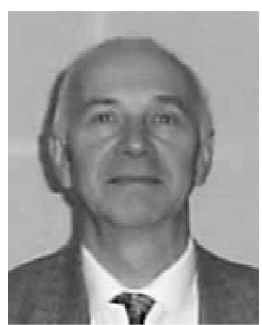

Andras Dan, Dr. is Professor with the Department of Electric Power Engineering, Budapest University of Technology and Economics. $\mathrm{He}$ received M.Sc. degree from Budapest Technical University in 1966, Ph.D. and D.Sc. degrees in Electrical Engineering from the Academy of Sciences in 1983 and 2005 respectively. His expertise is in power electronics, power quality and reactive power compensation especially associated with power system harmonics. 